\title{
THE MAGNETIC PROPERTIES OF NICKEL AND MAN- GANESE STEELS WITH REFERENCE TO THEIR METALLOGRAPHIC CONSTITUTION.
}

\author{
A Paper by Dr. E. Colver-Glauert (Sheffield) and Dr. S. Hilpert
} (Berlin) on "The Magnetic Properties of Nickel and Manganese Steels with Reference to their Metallographic Constitution" was read by Dr. Colver-Glauert.

The study of the magnetic properties of iron and its alloys has for a long time been one with a great fascination for metallurgists, and various theories have been put forward at different times in explanation thereof. One which has obtained wide credence is known as the allotropic theory, and assumes that at different temperatures iron undergoes allotropic modification, resulting in the production of materials with differing properties. If this theory be correct, it presents a very simple explanation of many curious phenomena, but in the authors' opinion it is untenable.

Broadly speaking, the allotropic theory states that below $75^{\circ} \mathrm{C}$. iron exists in the Alpha condition and is magnetic and soft, that at this temperature it changes into the Beta variety, which is unmagnetic and hard, and at $900^{\circ} \mathrm{C}$. it changes into the Gamma variety, which is equally unmagnetic but soft. It is stated that these varieties of iron may be preserved at room temperalures by a rapid quenching from the temperatures at which they are stable, and that the positions of the change points are modified by other elements which may be alloyed with the iron, to such an extent in certain cases that the Beta and Gamma varieties are stable at room temperatures. Following this it is assumed that all magnetic steels consist solely of Alpha iron, their properties resting entirely on their Alpha iron contents, and that all unmagnetic steels contain only Beta or Gamma iron. Similarly, the hardening of steels is alleged to be due to the conversion of Alpha into Beta iron.

The method usually adopted for estimating the magnetic change-point (Alpha $\rightleftarrows$ Beta) is to heat a piece of iron in proximity to a magnetic needle and to note the temperature at which the latter is no longer attracted by the iron, but assumes the $\mathrm{N}$. to $\mathrm{S}$. direction. That this method is inaccurate is readily seen when it is understood that all that is really shown is the point at which the magnetism induced in the iron by the weak field exerted by the needle is less than that of the earth's field. Osmond investigated his nickel steels by this method.

The pioneer work on nickel steels was conducted by Professor Hopkinson, who communicated his results to the Royal Society in I899 and Igoo. The work was done by a quantitative method, and proved that in the case of iron containing 25 per cent. of nickel the temperatures at which the alloy became unmagnetic and regained its magnetism were separated by several hundred degrees.

Contrary to Hopkinson, Osmond, as stated above, employed only a qualitative method. He investigated a very complete series of alloys, and took considerable care in their preparation and treatment, whereas Hopkinson's 
steels were practically as delivered by the makers, being treated purely from a physicist's standpoint, and according to metallurgists' views thereby losing much value. Nevertheless, Hopkinson's results remain as the only ones which have not been proved false by subsequent work.

From the results he obtained Osmond published the diagram reproduced in Fig. I, to which the authors have added the freezing-point curve. In the

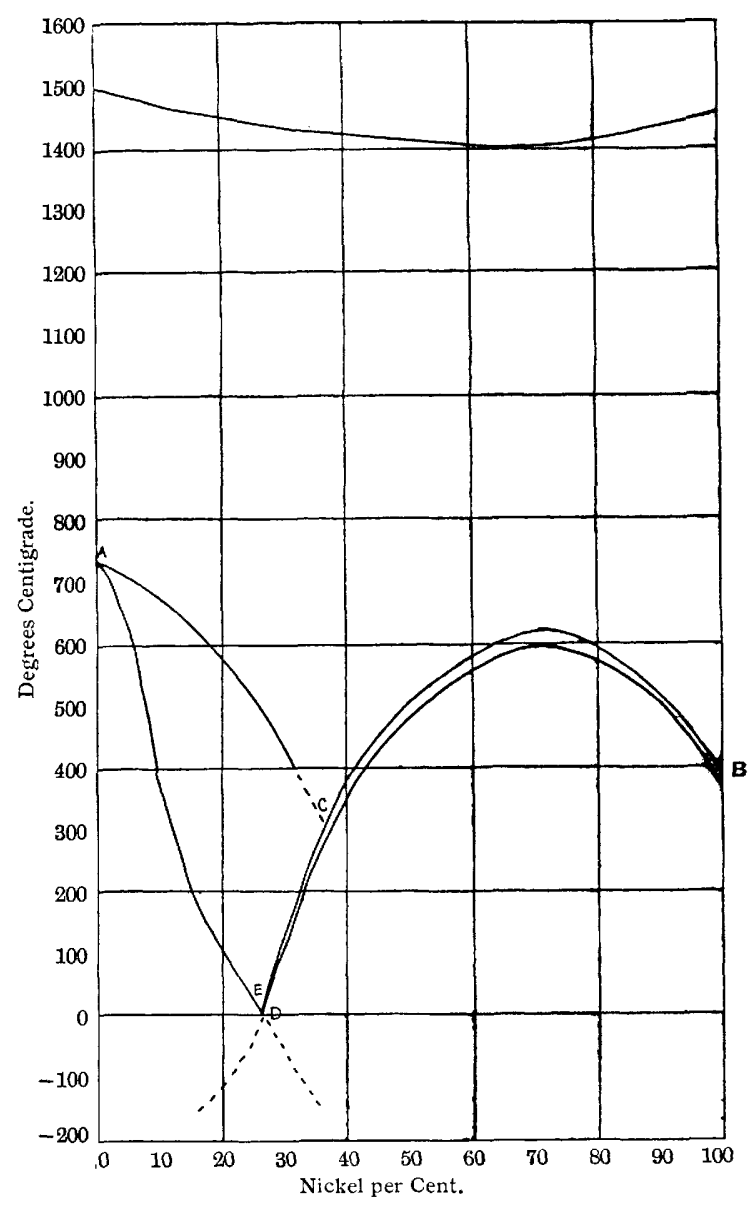

FIG. $\mathbf{x}$.

lower part of the diagram the lines $A$ to $C$ and $E$ to $B$ show the temperatures at which the alloys lose their magnetic properties on heating, and the lines $A D B$ the temperatures at which these are regained on cooling. This shows that with increasing percentages of nickel an increasing temperaturehysteresis is found, reaching a maximum with about 27 per cent. of nickel, above which percentage the transformation is reversible. If the allotropic theory be accepted as correct a very simple explanation of these curious phenomena is to hand, namely, that above $A C E B$ only Gamma iron exists, below $A D B$ only Alpha iron, whilst in the area enclosed by $A C D A$ either is stable. 
Similar phenomena to the above are observed in manganese steels, as first proved by the work of Sir Robert Hadfield.

Despite the enormous amount of research which has been done on these alloys, their properties are as yet by no means clearly understood. Even if iron is allotropic, and a given modification is unmagnetic at the temperature at which it is formed, it certainly does not follow that it is also unmagnetic when not at temperatures at which it is in a stable condition, for example, at normal room temperatures.

One method of investigating this subject is rapidly to quench the steels from various temperatures, and then estimate their magnetic properties at room temperature by a quantitative method. This was the method adopted by the authors for the present research.

The authors selected a series of alloys which, according to previously published researches, led one to expect a very typical steel from each part of the diagram to be included, and which have been considerably used in previous investigations of the magnetic properties of the systems and in connection with their allotropic modifications.

Table I. gives the analyses of the alloys employed :-

TABLE I.

\begin{tabular}{|c|c|c|c|}
\hline Steel No. & Nickel. & Manganese. & Carbon. \\
\hline $\begin{array}{l}1 \\
2^{*} \\
3 \\
4 \\
5 \dagger \\
6^{*} \\
7^{*} \\
8^{*} \\
9^{*} \\
10^{*}\end{array}$ & $\begin{array}{c}\text { Per Cent. } \\
5 \cdot 86 \\
\text { I2.60 } \\
20 \cdot 10 \\
24 \cdot 32 \\
27 \cdot 35 \\
32 \cdot 90 \\
- \\
-\end{array}$ & $\begin{array}{c}\text { Per Cent. } \\
0.20 \\
0.45 \\
0.51 \\
0.76 \\
0.64 \\
0.70 \\
4.58 \\
\text { I I.67 } \\
\text { I I. } 80 \\
\text { I I.70 }\end{array}$ & 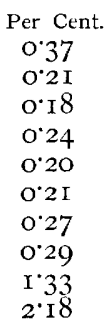 \\
\hline
\end{tabular}

The thermal treatment of the steels was carried out in a Heræus electric furnace. A finished magnetic test bar and a microsection from each steel were suitably fastened together and placed in the glazed porcelain tube. An atmosphere of nitrogen was maintained during the whole of the treatment and effectively prevented oxidation of the test pieces. The furnace was maintained at the desired temperature for at least a quarter of an hour, and then, in the case of the quenched specimens, one end of the tube was opened, and all the pieces pulled out together by means of a piece of wire previously attached and allowed to fall into a large tub of iced water, which was vigorously stirred. In the case of those test pieces which were to be slowly cooled, the current was switched off after the initial temperature had been maintained for a quarter of an hour and the pieces allowed to cool in the furnace, a slow stream of nitrogen being passed through all the time, cooling being complete in about eight hours.

When subjecting the specimens to temperatures below zero, the test piece and corresponding microsection were placed in one of the usual doublewalled receptacles, maintained at the desired temperature for ten minutes, 
and then allowed to regain room temperature. For temperatures down to $-50^{\circ} \mathrm{C}$. alcohol cooled with liquid air was used, between here and $-120^{\circ} \mathrm{C}$. the alcohol was replaced by petrol ether, and for the treatment at $-180^{\circ} \mathrm{C}$. the pieces were placed in boiling liquid air, which maintained the temperature constant within $2^{\circ}$ of the desired point.

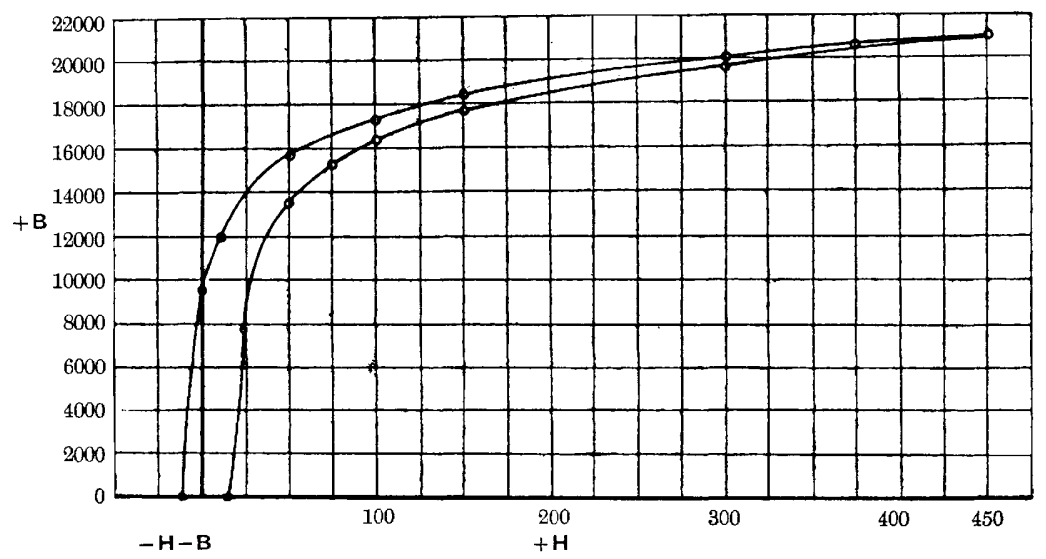

FIG. 2. -5 per cent. Nickel quenched from $600^{\circ} \mathrm{C}$.

The strongly magnetic steels were measured in the Du Bois magnetic precision balance, using bars $2 \pi(6 \cdot 3)$ centimetres long with ball ends. This size of test piece is very suitable for work of this nature, as the bars are not too long, so rendering the thermal treatment possible without giving rise to warping or variations in rapidity of quenching, \&c. For those steels which

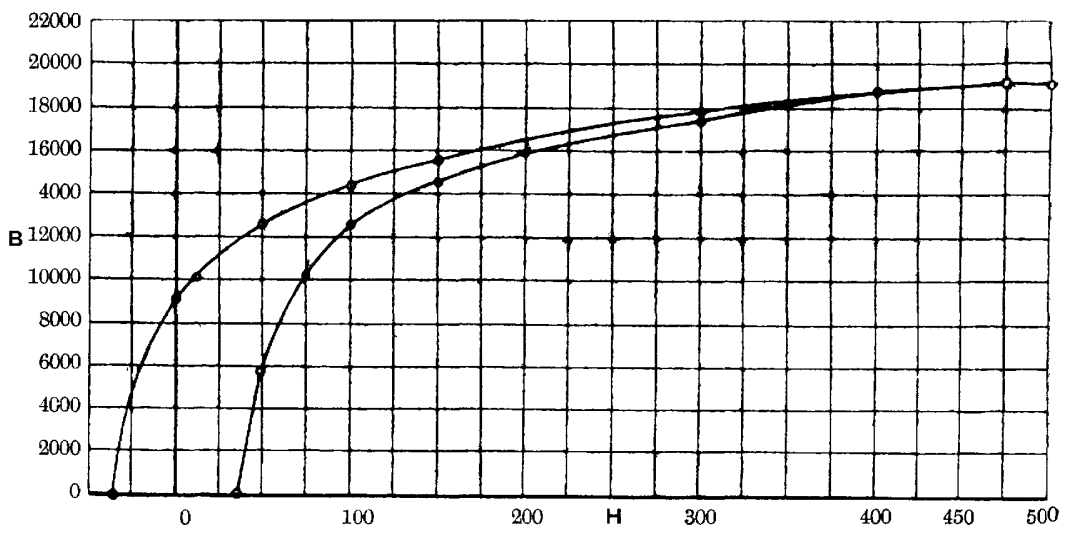

Fig. 3.-5 per cent. Nickel quenched from $900^{\circ} \mathrm{C}$.

were only feebly magnetic it was found that the Du Bois balance was not sufficiently sensitive, and the authors constructed a ballistic installation using test bars of the same dimensions as the Du Bois balance the sensitivity of which could be varied over a very wide range, and this was found to be quite satisfactory, although, of course, the hysteresis loop could not be taken. 
The metallographic examination was first made after the sections had been etched with the usual media, when the well-known structures of these alloys, consisting of so-called austenite, martensite, \&c., were observed. On etching with an aqueous solution of sulphurous acid, used as described by the authors in the Fournal of the Iron and Steel Institute, I9Io, vol. ii., a totally different

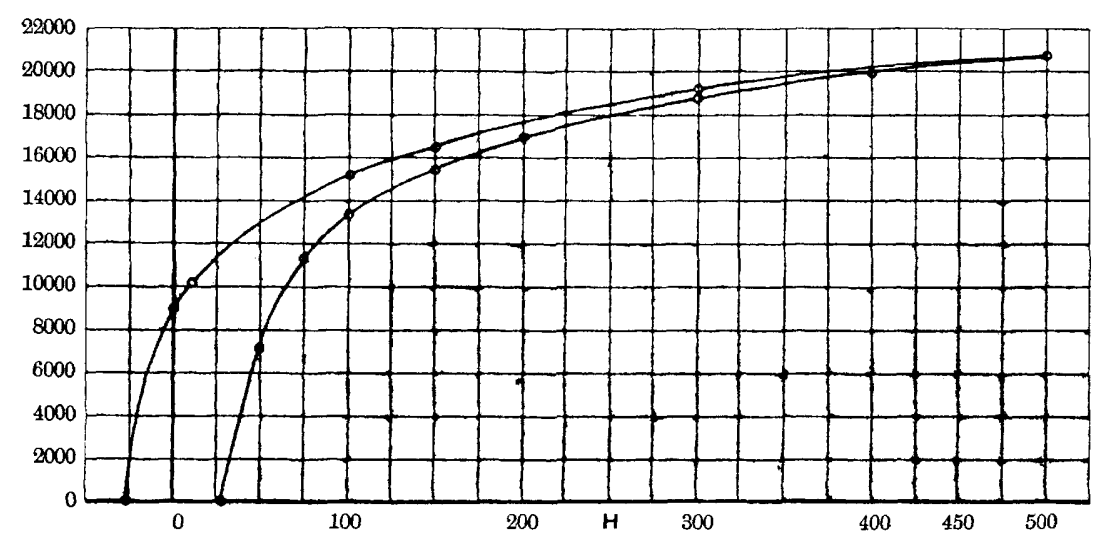

FIG. 4. -5 per cent. Nickel quenched from $1240^{\circ} \mathrm{C}$.

series of structures were obtained, and it is the latter that are reproduced herewith. These structures approximate that of meteoric iron very closely.

Specimens of the 5 per cent. nickel steel were quenched from $600^{\circ} \mathrm{C}$. $900^{\circ} \mathrm{C}$, , and $\mathrm{r}, 240^{\circ} \mathrm{C}$., and slowly cooled from $\mathrm{I}, 250^{\circ} \mathrm{C}$. The hysteresis

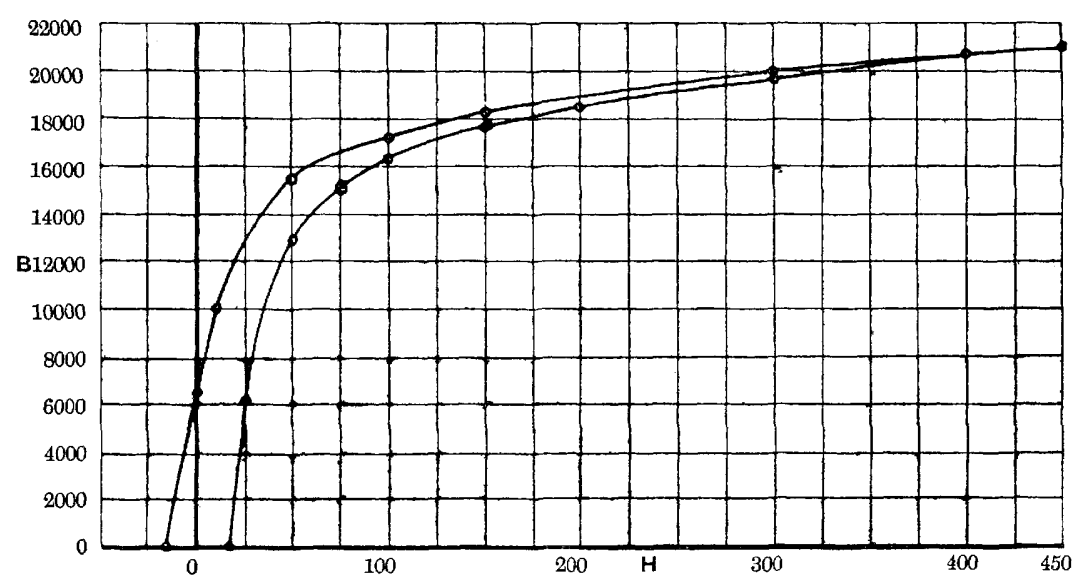

FIG. 5. -5 per cent. Nickel slowly cooled from $1250^{\circ} \mathrm{C}$.

curves from these as obtained in the $\mathrm{Du}$ Bois balance are reproduced in Figs. 2, 3, 4, and 5 respectively. The magnetic properties of the bars quenched from $600^{\circ} \mathrm{C}$. and slowly cooled are practically the same, but it is apparent that quenching from $900^{\circ} \mathrm{C}$. produces a considerably harder material, since in this specimen the magnetisability is at a minimum and the coercive force at a maximum. Quenching from $\mathrm{I}, 240^{\circ} \mathrm{C}$. gives rise to a 


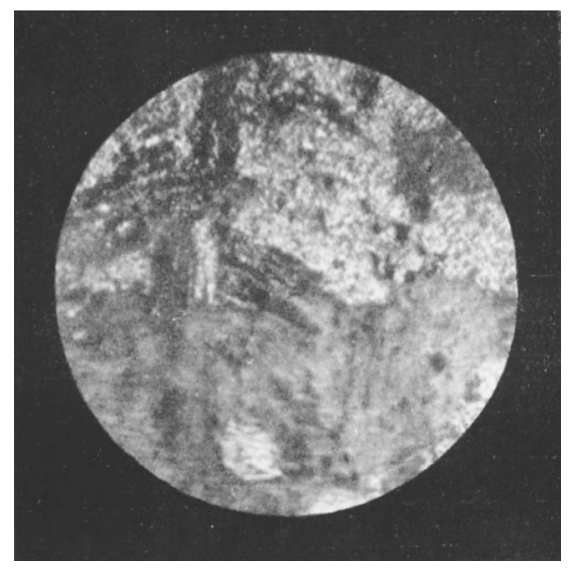

FIG. 6.

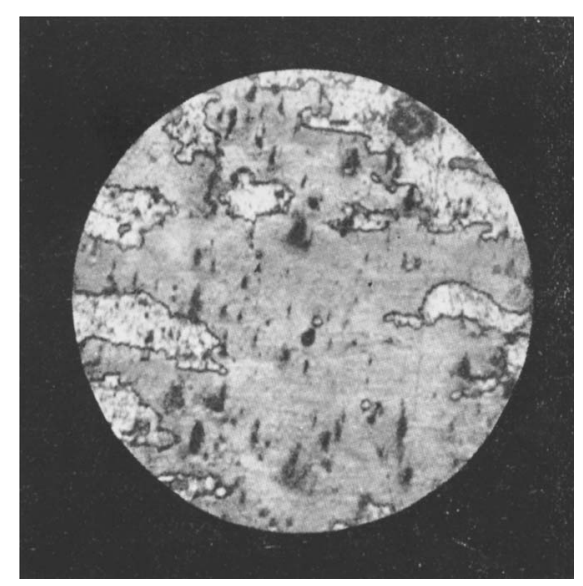

FIG. 22. 
material which is much softer than the last, and is practically as strongly magnetic as the slowly cooled specimen, although according to the allotropic theory the latter should consist entirely of Alpha iron, whilst the former was

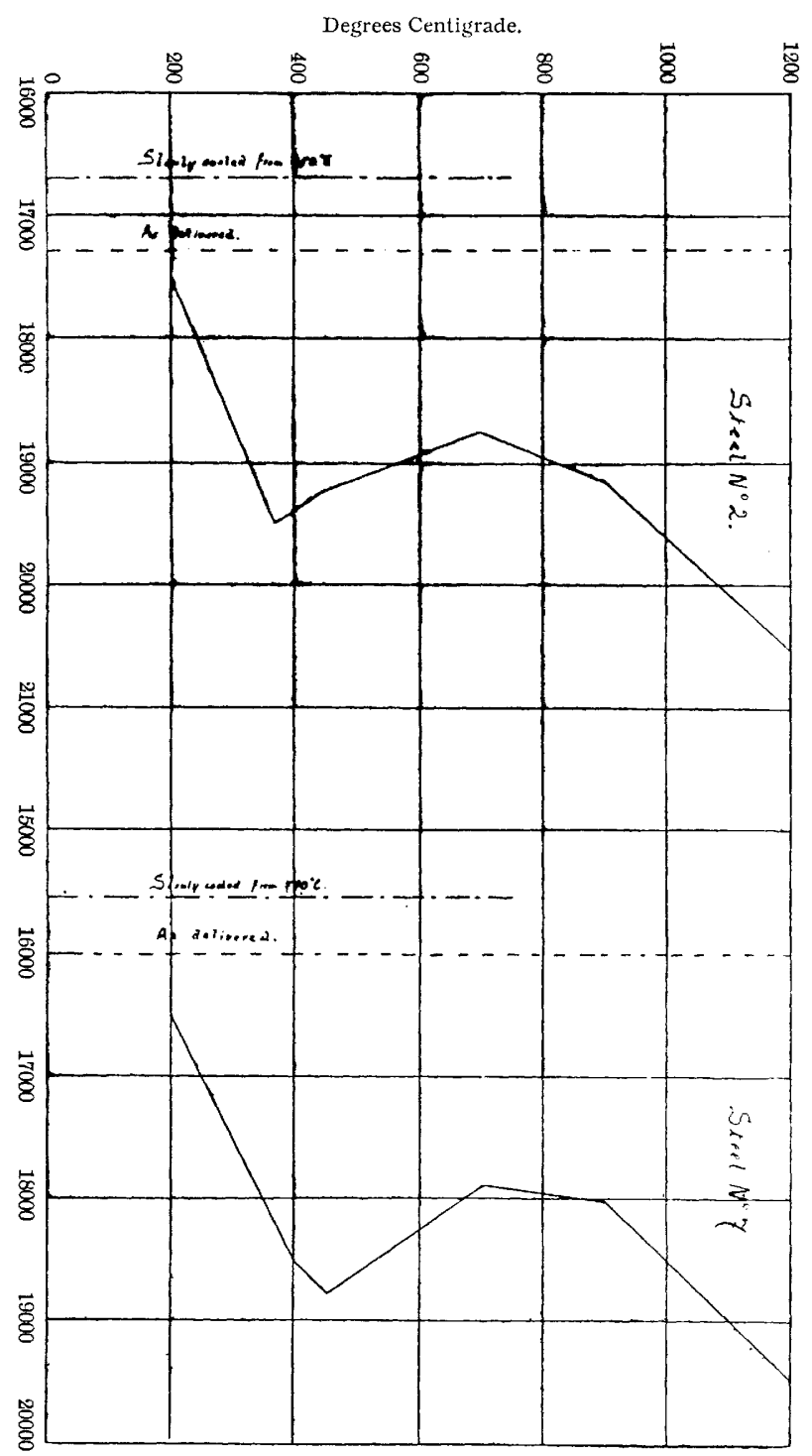

FIG. 7 .

quenched from a temperature well within the area of stability of the alleged Gamma iron.

Metallographic examination showed that the steel when slowly cooled or quenched from $600^{\circ} \mathrm{C}$. consists of ferrite and pearlite, only varying in the degree of lamellation of the latter constituent. Quenching from $900^{\circ} \mathrm{C}$. produces an entirely martensitic structure, whilst the specimen quenched 
from $\mathrm{I}, 240^{\circ} \mathrm{C}$. shows several constituents, one of which is martensitic, as shown in the photomicrograph reproduced in Fig. 6 (facing p. $13^{8}$ ).

The steels containing $\mathrm{I} 2$ and 20 per cent. nickel and 5 per cent. manganese exhibit very similar properties to the above. The results for a series of quenchings are depicted graphically in Figs. 7 and 8. In Fig. 7 the abscissæ denote the magnetisability at 800 c.g.s., whilst the ordinates show the

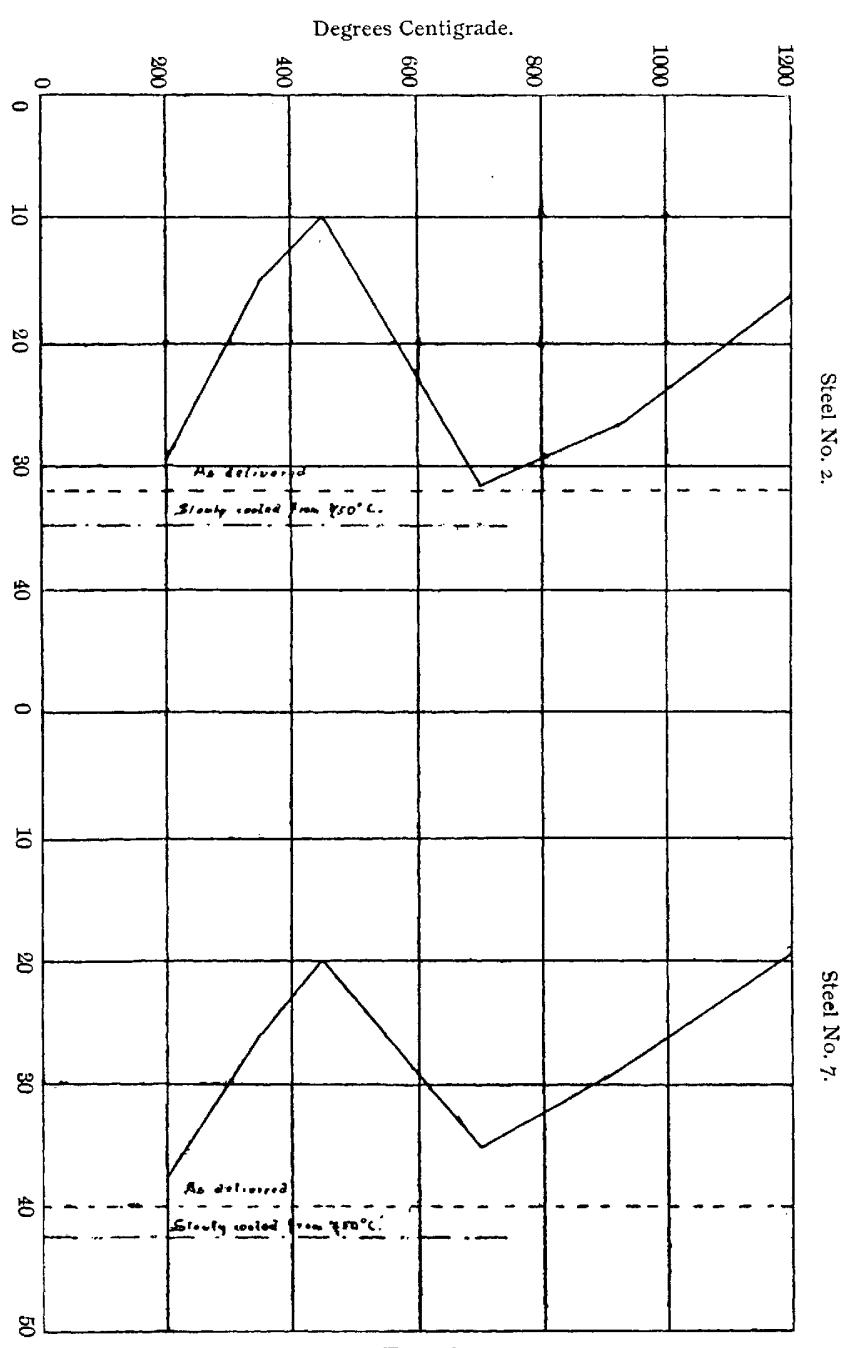

FIG. 8 .

temperatures from which the specimens were quenched. The magnetisability rises until the quenching temperature reaches $45^{\circ} \mathrm{C}$, sinks as the temperature rises to $900^{\circ} \mathrm{C}$., and reaches a maximum by quenching from $\mathrm{I}, 200^{\circ} \mathrm{C}$. Against this the slowly cooled material is the weakest magnetically. The coercive force is influenced in an exactly opposite manner, that is, when the magnetisability is a maximum the coercive force is at a minimum, and vice versa. This is graphically depicted in Fig. 8, the abscissa in this case 
being coercive force. In these cases again it is obvious that the magnetic properties cannot be explained by the assumption that they are solely dependent on Alpha and Gamma iron, since they follow exactly the same order as those of the 5 per cent. nickel alloy.

Cooling below zero produced no change in the foregoing steels.

The 25 per cent. nickel steel was, on account of its most remarkable properties, the one to which the authors have devoted most attention and on which by far the greatest amount of work has been done.

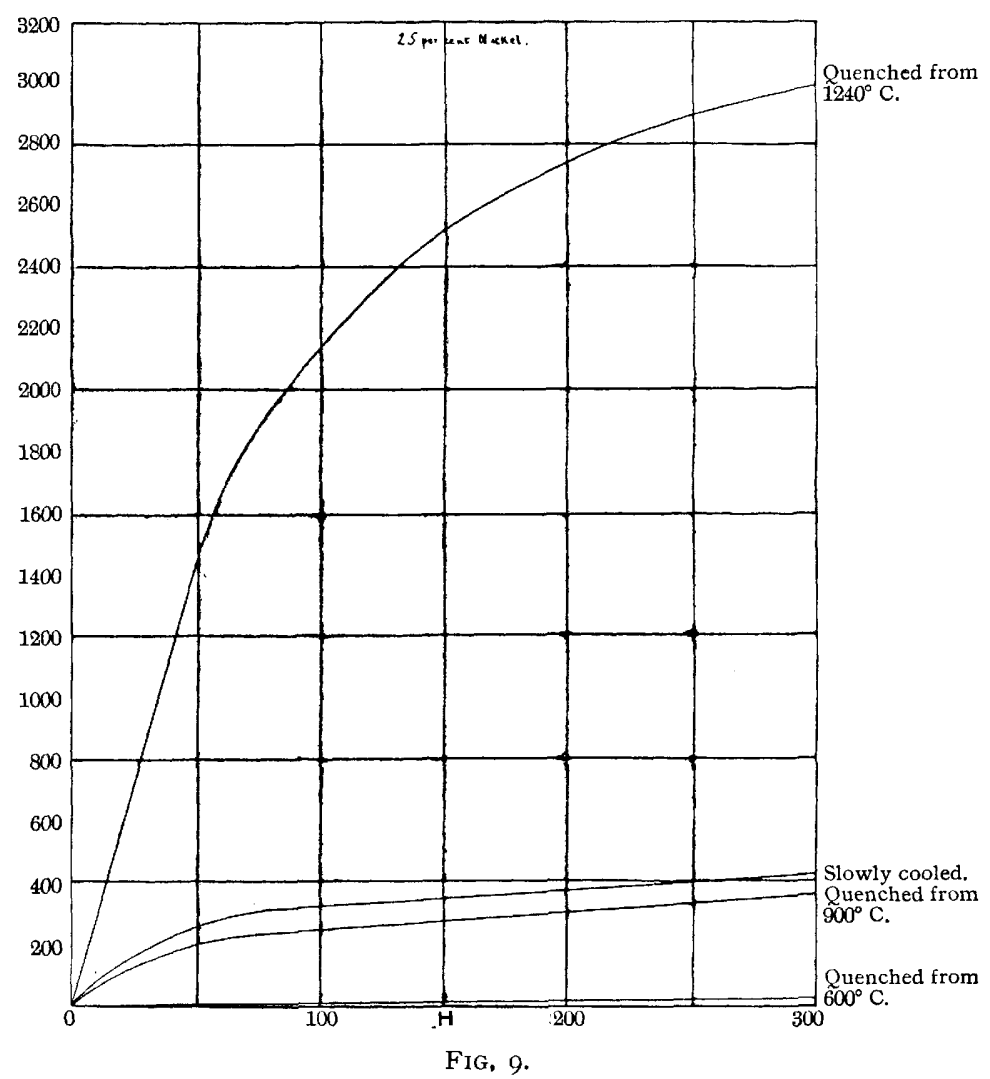

Preliminary experiments were made by quenching specimens from $600^{\circ}$, $900^{\circ}$, and $\mathrm{I}, 240^{\circ} \mathrm{C}$., and by slowly cooling from $\mathrm{I}, 250^{\circ} \mathrm{C}$. It was in the case of these test bars that the authors first found that the Du Bois balance could not be used, and they were therefore constrained to use the ballistic installation. The curves obtained from these specimens are shown in Fig. 9. It will be seen that the thermal treatment has had a most marked effect on this steel. Whilst the specimen quenched from $600^{\circ} \mathrm{C}$. is practically unmagnetic, the one quenched from $900^{\circ} \mathrm{C}$. is already measurable, and could indeed be moved with a weak horseshoe magnet. Quenching from $\mathrm{I}, 240^{\circ} \mathrm{C}$. has, however, had a most remarkable effect, and has produced a material approximately one-seventh as magnetic as pure iron. The slowly cooled specimen is also comparatively strongly magnetic. The authors would again point out that the results shown by this steel are in no way 
compatible with the allotropic theory ; in fact, if that theory were correct it would appear that the magnetic order of the test bars would be the exact opposite to that found. In connection with these preliminary experiments the above specimens were next cooled to $-50^{\circ} \mathrm{C},-,-100^{\circ} \mathrm{C}$, and - I $80^{\circ} \mathrm{C}$, magnetic measurements being taken at room temperature after each step. This showed that there is no sudden change at a definite temperature upon which the material suddenly becomes completely magnetic (Hopkinson shows a complete change at $-52^{\circ} \mathrm{C}$., and Guillet at $0^{\circ} \mathrm{C}$.), but that as the temperature is lowered the magnetisability is gradually increased. Whether this change is complete at $-I 80^{\circ} \mathrm{C}$. or not, the authors are at present unable to state, since at the time of conducting the present research this was the lowest

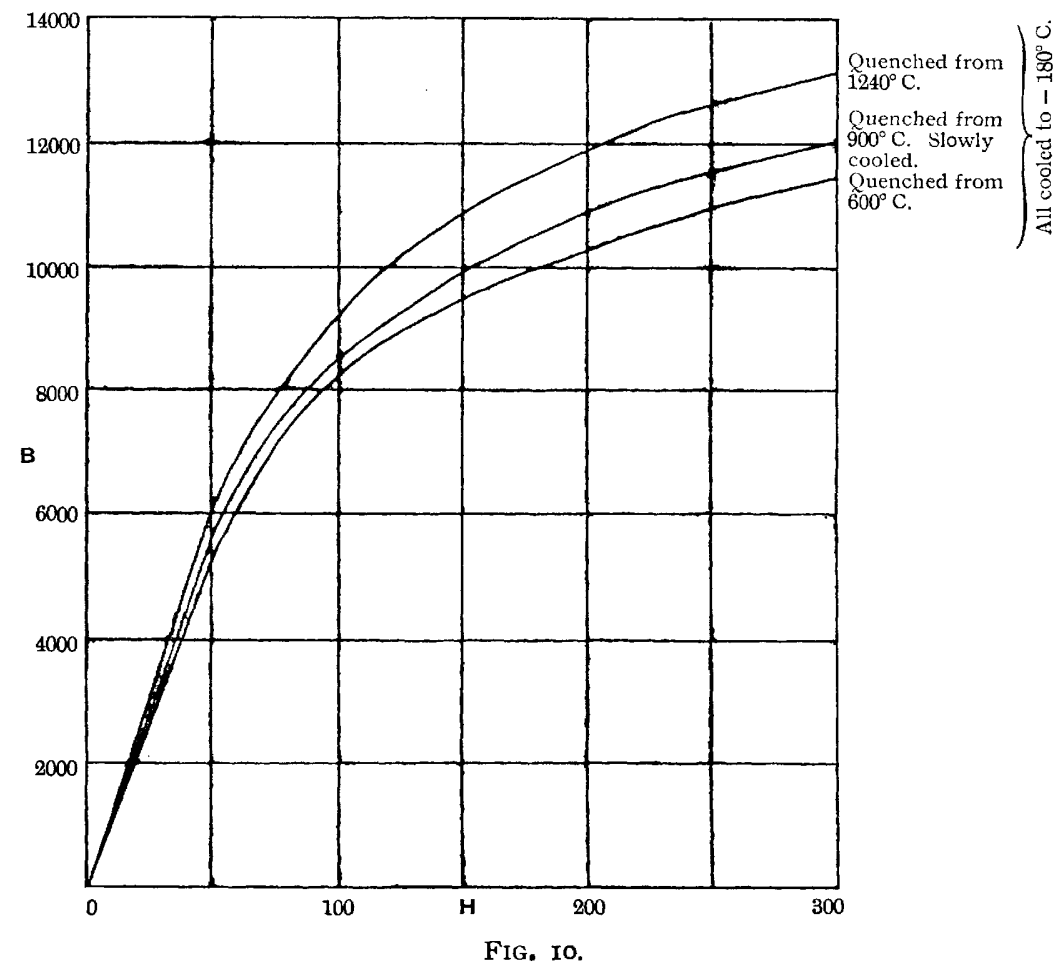

temperature they were able to produce, considering the comparatively large size of the test bars being used, but they hope in the near future to have access to a considerable quantity of liquid hydrogen, and will then investigate the steels in a still lower range of temperature. This treatment showed that the cooling did not transform all the materials produced by the previous thermal treatment into one common material, since the specimen originally quenched from $1,240^{\circ} \mathrm{C}$. remains stronger than the others by practically the original difference, and though the bars quenched from $900^{\circ} \mathrm{C}$. and slowly cooled now coincide, they are still in advance of the one quenched from $600^{\circ} \mathrm{C}$. Ballistic curves obtained from the steel thus treated are shown in Fig. ro. In this state the steels were of course measurable in the Du Bois balance, and in order to show the type of curve possessed by the steel, Fig. Ir is reproduced, and depicts the hysteresis loop of the bar quenched from 
$\mathrm{I}, 240^{\circ} \mathrm{C}$. after being cooled to $-180^{\circ} \mathrm{C}$. It will be seen that the type of curve is that of a very hard material and that even at a field strength of 450 the material is by no means saturated. (The saturation point of iron is about I3o.) Another remarkable point in this curve is the high value of the coercive force, although the retentivity is only low.

The products were now carefully heated in a non-oxidising atmosphere in an electric furnace, the progression being made by steps of $50^{\circ} \mathrm{C}$., the bars being tested, at room temperatures, after each step. This proved that heating up to $450^{\circ} \mathrm{C}$, results in a slight gradual increase in the magnetisability, above which temperature it falls away fairly rapidly, reaching a minimum which is practically zero at $700^{\circ} \mathrm{C}$. In this neighbourhood the authors found considerable difficulty in obtaining concordant results, as totally different products were apparently produced if the bars were removed and quenched on a heating or cooling curve, and this will be readily understood when the peculiar behaviour of the steel in this region of temperature is explained later. On continuing the heating above $700^{\circ} \mathrm{C}$. the magnetisability again

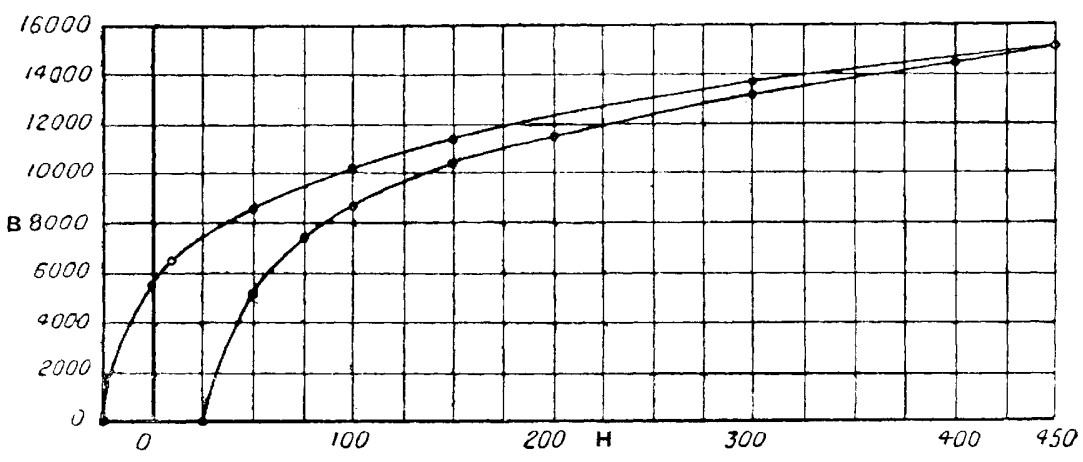

Fig. II. -25 per cent. Nickel quenched from $1240^{\circ} \mathrm{C}$. Cooled to $-180^{\circ} \mathrm{C}$.

rises, reaching a maximum at $95^{\circ} \mathrm{C}$., falls again with a minimum at $\mathrm{r}, 05^{\circ} \mathrm{C}$., and after this point continues to rise gradually, at least to the top limit of the author's investigations, viz. $1,240^{\circ} \mathrm{C}$.

It has been shown that if this steel be quenched from $600^{\circ} \mathrm{C}$. (not having been previously heated much above this point) or about $750^{\circ} \mathrm{C}$. it is unmagnetic, but if quenched from or above $900^{\circ} \mathrm{C}$. it is magnetic, and it might therefore be assumed that a change-point or line of stability exists in this region, above which there is a magnetic product and below which an unmagnetic one; but if this were the case a slowly cooled steel must necessarily be unmagnetic, whereas the opposite is the case. In all specimens of the steel which were slowly cooled the same fairly high degree of magnetisability was found. The curve between $450^{\circ} \mathrm{C}$. and $95^{\circ} \mathrm{C}$. was next very carefully investigated, and it was found that on quenching or slowly cooling the steel from any given point on this curve the same degree of magnetisability was retained, whilst all specimens slowly cooled from above $950^{\circ} \mathrm{C}$. exhibited the maximum. From this it was only possible to assume that a second irreversible temperature-hysteresis loop existed here, and in order to ascertain that no mistake had been made the experiments were repeated several times.

The whole series of experiments were now repeated, with the interpolation 
of many new stages, both above and below zero, and finally the authors were able to construct a diagram showing the complete changes which this steel undergoes between the limits of $\mathrm{I}, 240^{\circ} \mathrm{C}$. and $-\mathrm{r} 80^{\circ} \mathrm{C}$. This is reproduced in Fig. 12. The lower temperature-hysteresis loop of this diagram is essentially the one discovered by Hopkinson, with the exception of such details as regards temperature of changes and completeness thereof which have been previously noted. The upper temperature-hysteresis loop accounts for the difficulties experienced by the authors in their preliminary experiments, and it will be understood that the steel must follow the curved line to the

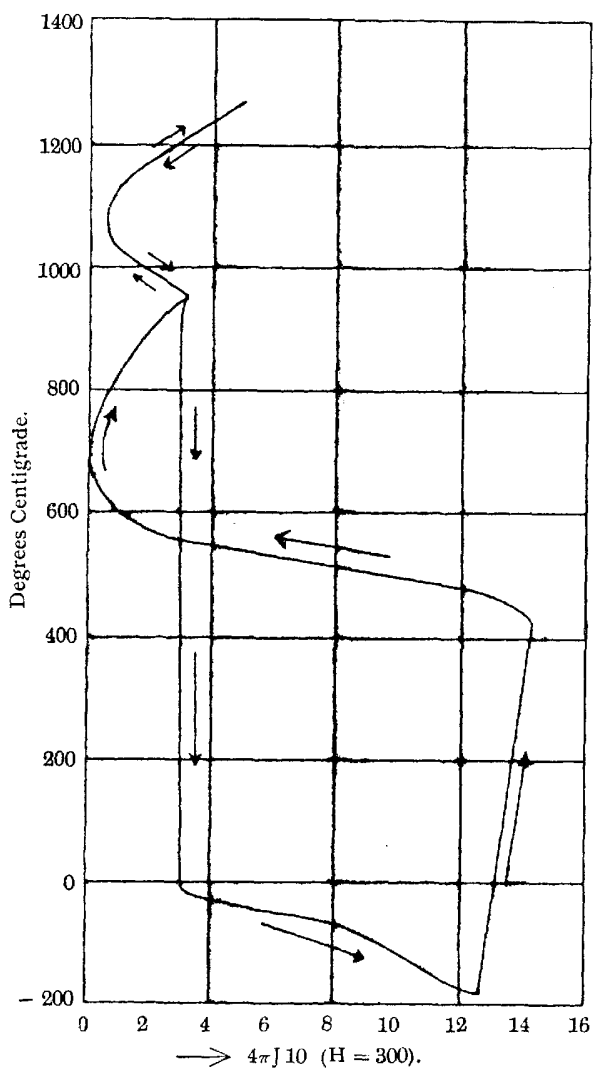

FIG. I2.

left on heating and the straight line to the right on cooling. The steel, when cooled slowly from a high initial temperature, must follow the vertical line from $950^{\circ} \mathrm{C}$., but a steel cooled from any intermediate point will cool along one of an infinite number of vertical lines from any point on the curve between $550^{\circ} \mathrm{C}$. and $950^{\circ} \mathrm{C}$. The only means by which the steel may be rendered totally unmagnetic is by quenching or cooling from $700^{\circ} \mathrm{C}$. when this point is reached on heating. Above $900^{\circ} \mathrm{C}$. the changes are reversible ; that is, the same line is followed both on heating and on cooling.

Metallographic examination of this steel after the various thermal treatments described showed that by etching with sulphurous acid very different structures were developed from those produced by the more generally employed 


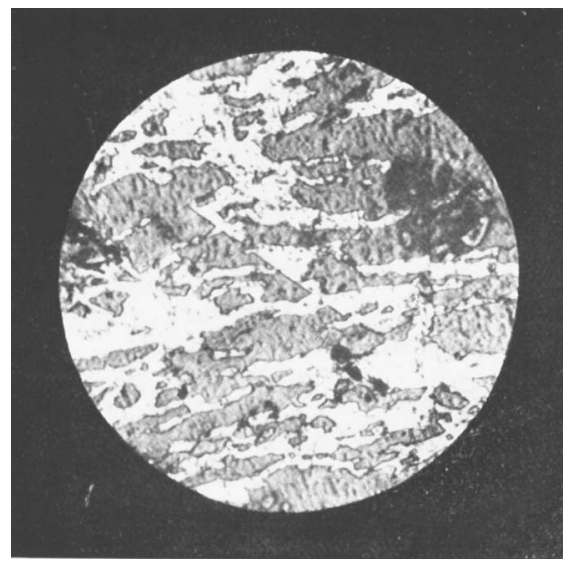

FIG. I3.

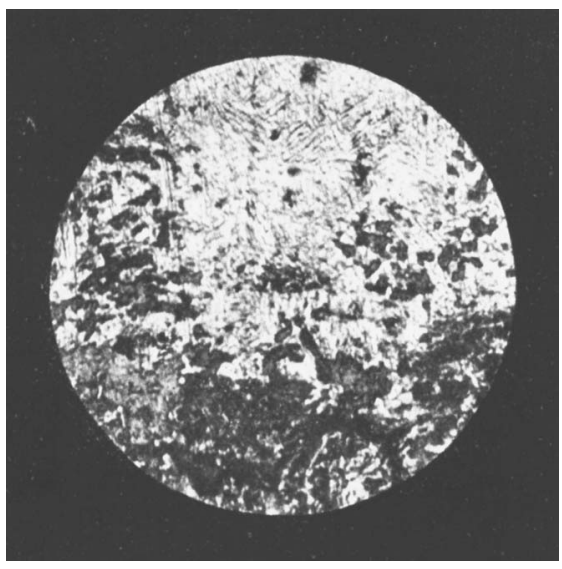

FIG. I5.

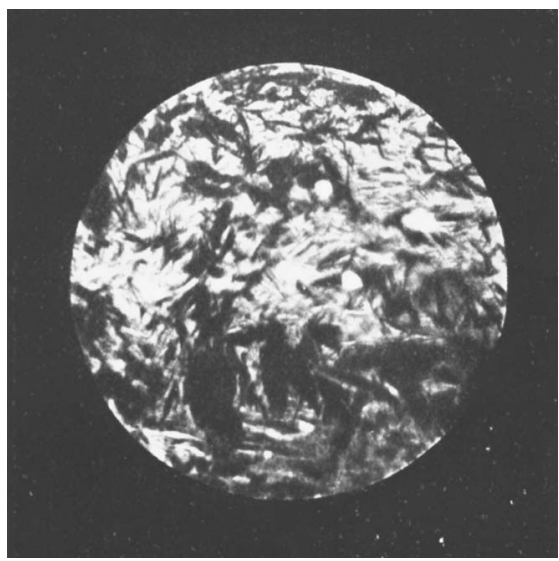

FIG. 17.

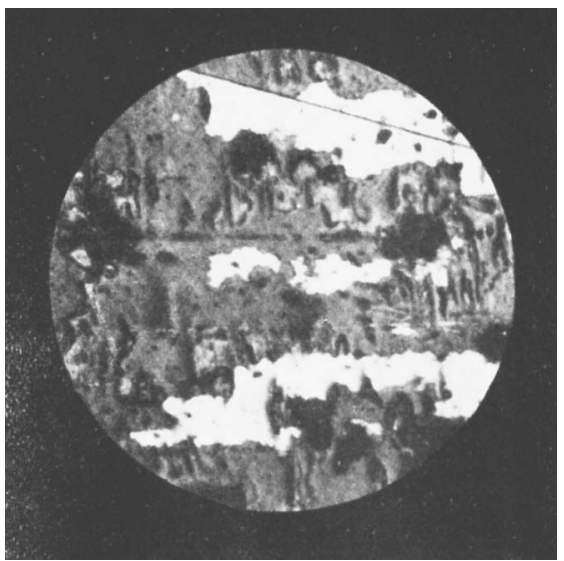

FIG. I4.

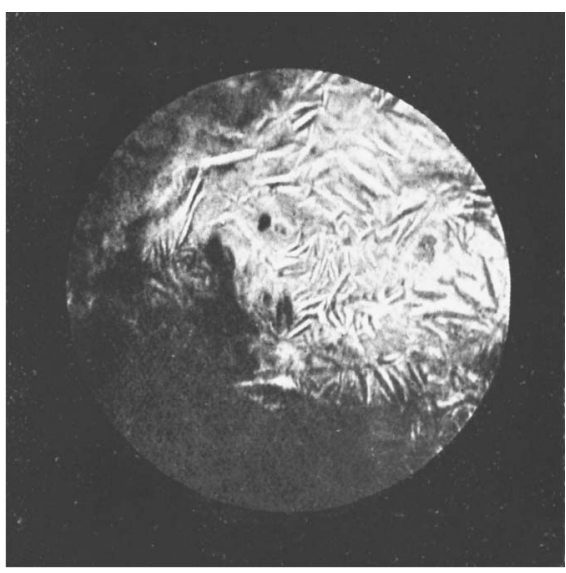

FIG. I6.

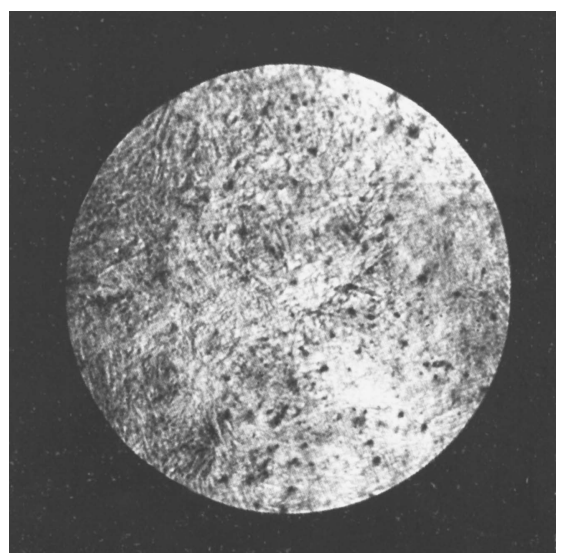

FIG. 18. 
media. Typical photomicrographs are reproduced herewith (facing p. 144). Fig. $I_{3}$ depicts the structure of the specimen when quenched from $600^{\circ} \mathrm{C}$, and is also typical of others up to $900^{\circ} \mathrm{C}$. Three constituents are visible-one pale etching, one darker, and the third occurring as thin dark bands between the other two. Fig. I4 shows the structure obtained on quenching from $\mathrm{I}, 24 \mathrm{O}^{\circ} \mathrm{C}$., and is of a very similar type to that of the previous specimen. Fig. ${ }_{5} 5$ is the structure of the slowly cooled specimen, and it is observable that in this case one of the constituents is martensitic in nature. The presence of several constituents in these structures is somewhat remarkable, since, according to the freezing-point diagram of this series of alloys, only mixed crystals occur, which should produce a homogeneous structure. A structure more after this nature is obtained on etching with an electrolytic medium, and has frequently been depicted and called austenite. Against this, however, may be noted the structure of those meteoric irons consisting of a nickel iron alloy, which almost invariably show several constituents on being etched. As to the reason for the different etching effects obtained of these alloys, the authors can only state that they are still of the opinion that their medium is purely chemical in its attack and therefore only differentiates constituents with differing chemical composition, whereas the electrolytic media differentiate by the potential of the constituents, and it is quite possible for various parts of the same compound to have different potentials, due possibly to molecular orientation, or for different compounds, under certain conditions, to possess similar potentials. Further, it is possible that during its life as a meteorite the nickel iron alloy undergoes some change whereby its constituents assume different potentials, thus enabling them to be developed by electrolytic media, and that the time factor of this change is so great that it is impossible of artificial reproduction. On subjecting the specimens to a temperature of $-50^{\circ} \mathrm{C}$. the structures become more martensitic, and this development may be observed without further etching, as it stands out in relief, as shown by Fig. 16, which may be regarded as typical of the set. The appearance on reetching is shown in Fig. 17. Cooling to $-100^{\circ} \mathrm{C}$. renders the material completely martensitic, as depicted in Fig. 18 , which shows a section after reetching. Further cooling produced no further change in these structures, although a very marked change in the magnetic properties occurs below this point. The martensitic structure remains unchanged during the subsequent heating until the unmagnetic zone is reached, when there is a sudden reappearance of the original structure as depicted in Fig. I3.

These results, when considered in relation to the magnetic properties, are so widely divergent that the authors are unable to observe any real connection between the two. The slowly cooled specimen originally possessed a partly martensitic structure, although it was considerably less strongly magnetic than the one quenched from $\mathrm{I}, 240^{\circ} \mathrm{C}$., which was not at all martensitic. Neither was the slowly cooled specimen as strongly magnetic as the latter when both had been rendered completely martensitic by cooling. Thus steels with similar structures have very different magnetic properties and some with different structures have similar properties, whilst marked magnetic changes may take place in the material without the structure showing any change whatever.

The 27 per cent. nickel steel was found to be very similar in its properties to the 25 per cent., but the authors were unable to find the upper temperature-hysteresis loop (Fig. I2) found in the latter alloy.

The ro per cent. manganese steels were found to possess very similar properties to the irreversible nickel steels.

In connection with these nickel steels the authors had considered that the 
relatively high magnetisability possessed by them when quenched from high temperatures must be due to the formation at that temperature of a strongly magnetic compound which persisted through all subsequent treatments, and they were able to find conclusive proof of this in the manganese steels. Steel No. 8 showed this very clearly in specimens quenched from $\mathrm{I}, 200^{\circ} \mathrm{C}$. Fig. I9 is a diagram showing the changes occurring in this steel during thermal treatment. The left-hand curve shows the magnetic properties when slowly cooled from $700^{\circ} \mathrm{C}$., whilst the right-hand one depicts the behaviour of the steel when quenched from $\mathrm{I}, 200^{\circ} \mathrm{C}$. This diagram shows that at least two constituents must be present, of which only one undergoes any change by

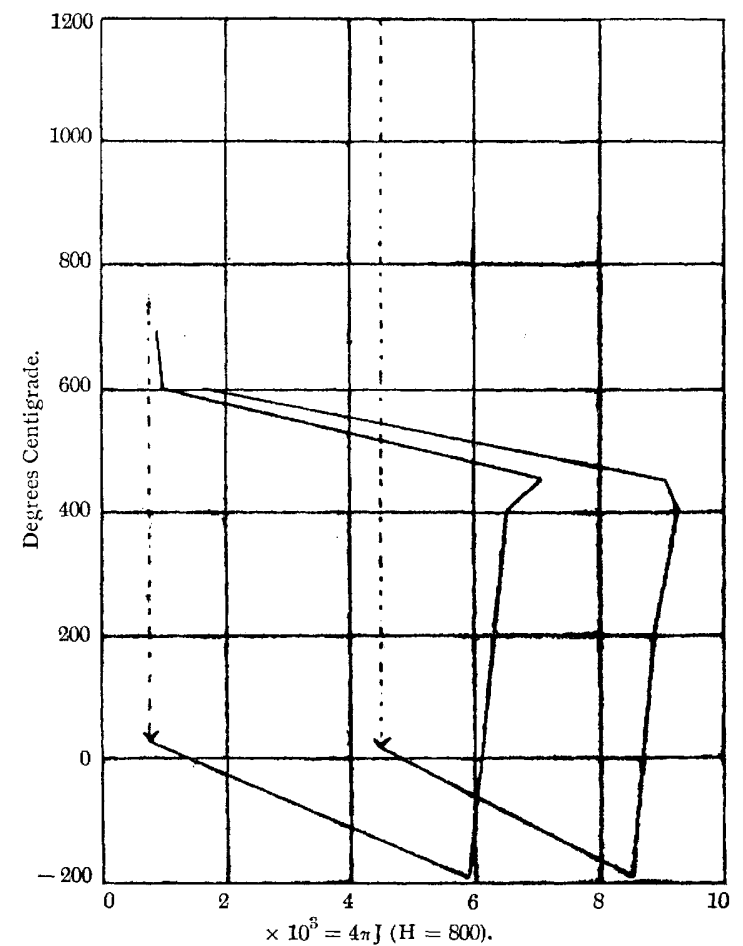

FIG. I9.

cooling to $-180^{\circ} \mathrm{C}$, and further, that the constituent produced by quenching from $1,200^{\circ} \mathrm{C}$. must be per se strongly magnetic.

Steel No, 9, containing I per cent. of carbon, shows this even more markedly. This greater difference is clearly shown by the diagram Fig. 2o, depicting a similar set of treatments to Fig. I9. This enhanced difference may possibly occur because in the slowly cooled steel the carbide is present as free carbide and is not changed by the treatment in liquid air, whereas in the specimen quenched from $\mathrm{I}, 200^{\circ} \mathrm{C}$. the carbide is dissolved in the iron and undergoes the change with the solute. Steel No. Io ( 2 per cent. carbon) showed similar properties, but the difference between the two loops was even more marked.

The 33 per cent. nickel steel exhibits totally different properties from those of the steels previously considered. It is almost unaffected by thermal 


\section{NICKEL AND MANGANESE STEELS}

treatment, and the question arises as to whether there is any connection between this fact and the proximity of the steel to Invar metal in composi

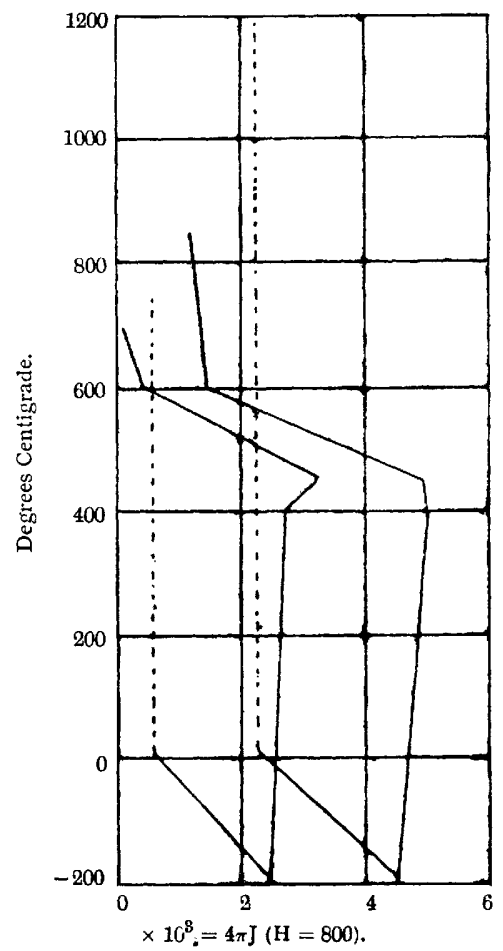

FIG. 20 .

tion, the remarkable physical properties of the latter in regard to expansion under the influence of temperature being well known.

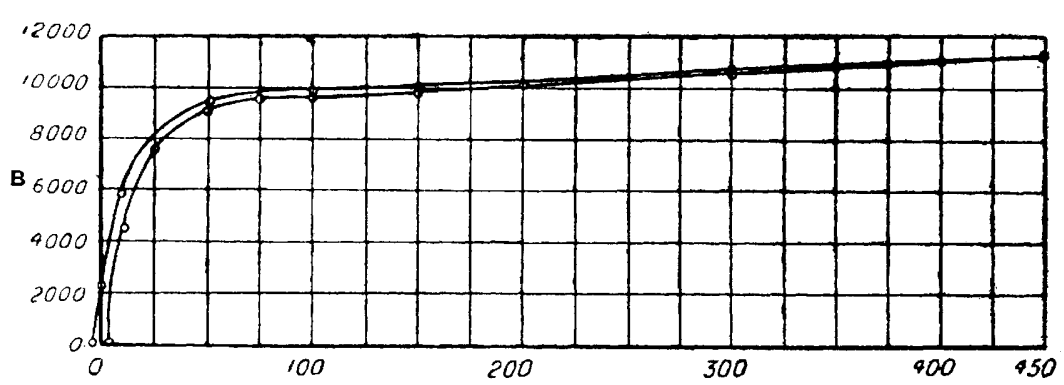

FIG. 2I. -35 per cent. Nickel slowly cooled from $125 \mathrm{C}^{\circ} \mathrm{C}$.

The slowly cooled specimen was the most strongly magnetic, and the magnetisability gradually decreased to a slight extent as the quenching temperature was increased to $1,240^{\circ} \mathrm{C}$. The whole series, however, remain magnetically very soft, the coercive force being exceptionally small, the 


\section{I48 THE MAGNETIC PROPERTIES OF STEELS}

saturation point low and with a fairly high retentivity, although the maximum induction is only about half that of pure iron. A typical curve as obtained by the Du Bois balance is shown in Fig. 2I. The properties of this steel are so different from others of the series that it seems to be a definite and separate compound.

In the case of this steel metallographic examination showed the presence of several constituents, a typical structure being depicted in Fig. 22 (facing p. ${ }_{13}^{8}$ ).

Neither the magnetic properties nor the metallographic structures of this steel were in any way changed on subjecting to cooling to $-180^{\circ} \mathrm{C}$.

\section{Conclusions.}

After investigating a series of nickel and manganese steels with reference to the influence of thermal treatment on their magnetic and metallographic properties, the authors' main conclusions are :-

I. There is a distinct connection between thermal treatment and magnetic properties.

2. Any modification which is produced by quenching these alloys from $\mathrm{I}, 200^{\circ} \mathrm{C}$. is in all cases, at room temperatures, strongly magnetic.

3. It is possible to define various constituents by their magnetic properties.

4. In the case of the 25 per cent. nickel steel two superimposed temperature-hysteresis loops exist.

5. A definite connection between metallographic structure and magnetic properties does not exist.

6. The metallographic structure of artificial nickel iron alloys closely approximates that of meteoric iron.

7. That the allotropic theory of the magnetic properties of iron alloys is not upheld by the facts. 